\title{
Enhanced Classical Tafel Diagram Model for Corrosion of Steel in Chloride Contaminated Concrete and the Experimental Non-Linear Effect of Temperature
}

\author{
Raja Rizwan Hussain ${ }^{1)}$
}

\author{
(Received January 6, 2010, Revised October 3, 2010, Accepted October 29, 2010)
}

\begin{abstract}
The chloride ion attack on the passive iron oxide layer of reinforcement steel embedded in concrete under variable temperature environment is influenced by several parameters and some of them still need to be further investigated in more detail. Different school of thoughts exist between past researchers and the data is limited in the high temperature and high chloride concentration range which is necessary with regards to setting boundary conditions for enhancement of tafel diagram model presented in this research. The objective of this paper is to investigate the detrimental coupled effects of chloride and temperature on corrosion of reinforced concrete structures in the high range by incorporating classical Tafel diagram chloride induced corrosion model and laboratory controlled experimental non-linear effect of temperature on corrosion of rebar embedded in concrete.
\end{abstract}

Keywords: reinforced concrete, corrosion, chloride, temperature, modeling.

\section{Introduction}

High alkaline environment of good quality concrete forms a passive film on the surface of the embedded steel which normally prevents the steel from further corroding. However, under chloride attack and high temperature, the passive film is destroyed, and the steel spontaneously corrodes. Therefore, it is necessary to conduct deep investigation to understand the mechanisms of chloride induced corrosion under variable temperature in the high range for which the previous research is limited. ${ }^{1,2}$ The data available from the past clearly shows that the modeling of chloride induced corrosion needs to be thoroughly revised incorporating classical theories along with reality based experimental equations so that the corrosion of real structures can be predicted with accuracy. ${ }^{2,3}$ Also, the experiments conducted by various researchers in the past show a varying trend in context with the effect of temperature on the rate of corrosion with a clear need of further investigation to clarify and/or modify the present state-of-the-art in this area of research.

Investigation of the severe environmental effects of chloride and temperature on corrosion of steel in concrete both by experimentation and modeling approach by clarifying the mechanisms involved is the major objective of this research paper. The corrosion phenomenon is influenced by several factors and some of them have been overlooked in the past research works and have difference of opinion among themselves. Also it was found that

\footnotetext{
${ }^{1)}$ CoE-CRT, Civil Engineering Dept., College of Engineering, King Saud University, Riyadh, PO Box: 800, 11421, Saudi Arabia. Email: raja386@hotmail.com.

Copyright (c) 2010, Korea Concrete Institute. All rights reserved, including the making of copies without the written permission of the copyright proprietors.
}

the experimental data for the coupled effect of chloride and temperature on corrosion of reinforcement especially in the high temperature range and high chloride concentration is limited. In this research a classical Tafel diagram technique ${ }^{5}$ has been reborn with an entirely new approach of semi-empirical modeling and has been verified with improved and enhanced experimentation initially adopted from the previous research ${ }^{6}$ and standard specifications. $^{7}$

\section{Electro-chemical-thermo-hydro-dynamic model 'DuCOM',}

A three dimensional finite element model is implemented in this research as a general framework for corrosion assessment and numerical analysis of RC structures subjected to severe environmental conditions such as chloride. A general frame work of mass and ion equilibrium equations and an electro-chemical reaction model of corrosion in reinforced concrete has been presented elsewhere. ${ }^{2,3}$ Thus the influential parameters on the theorem of corrosion process for severe environmental effects are determined experimentally and simulated in numerical terms for the enhancement of existing model in this research. The reliability of this model is verified through comparison of simulation with experiment results.

The constituent material models employed in DuCOM are formulated based on micro-mechanical phenomena such as hydration, moisture, transport and cementitious microstructure formation. Their strong interrelationships are taken into account by real time sharing of material characteristic variables across each sub-system. The development of multi-scale micro pore structures at early age is obtained based on the average degree of cement hydration in the mixture. The non-linearity in corrosion process and severe envi- 


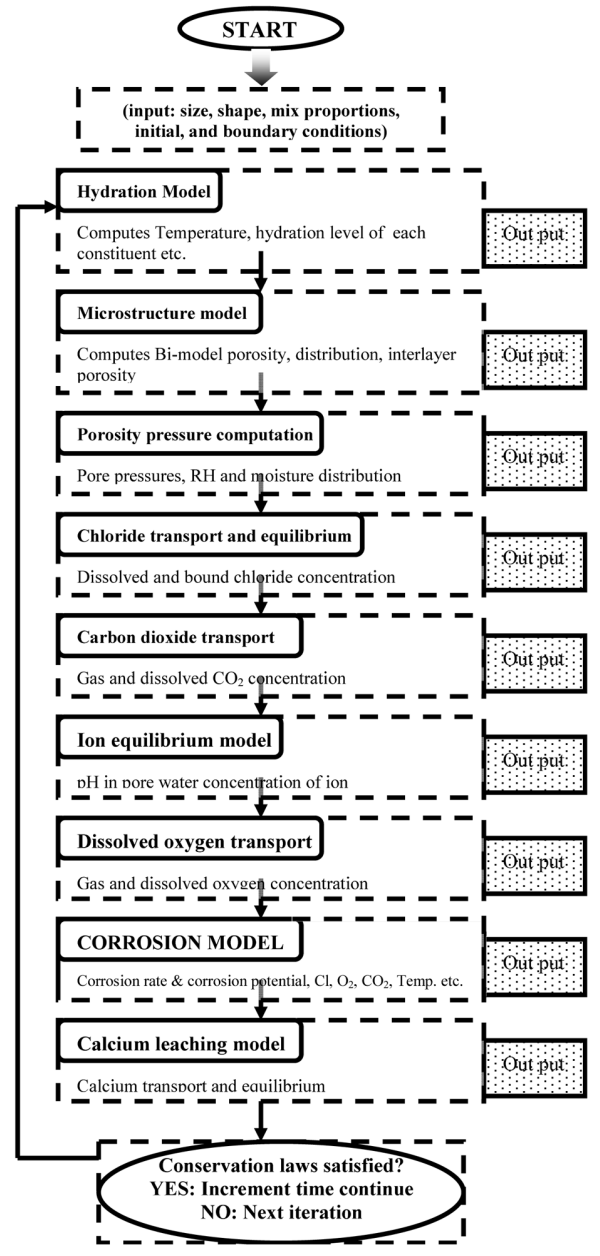

Fig. 1 Visualization of the unified frame work of DuCOM.

ronmental effects along with various connected subroutines to acquire the parameters necessary for the computation of corrosion are taken into account automatically in the unified framework of this program which is the beauty and originality of this model (Fig. 1).

\section{Experimentation}

\subsection{Materials and mix proportions}

Ordinary Portland cement (OPC) as per JIS R5210 specifications was used throughout this research. Natural river sand passed through JIS A1102 sieve No. 4 (4.75 mm openings), was used as fine aggregate for all concrete mixes. Its density and water absorption were $2.65 \mathrm{~g} / \mathrm{cm}^{3}$ and $2.21 \%$, respectively. Crushed limestone with a maximum size of $20 \mathrm{~mm}$ was used as coarse aggregate with density of $2.70 \mathrm{~g} / \mathrm{cm}^{3}$ and water absorption $0.59 \%$. It was retained on the sieve No. 4 (4.75 mm openings) and cleaned before being used. Deformed round carbon steel bars of $13 \mathrm{~mm}$ in diameter were used as reinforcing steel. The surface of steel bar was polished by sand paper No. 200. Finally, steel bar was

Table 1 Mix proportions.

\begin{tabular}{c|c|c|c|c|c}
\hline Specimen & W/C & $\begin{array}{c}\text { Binder } \\
\left(\mathrm{Kg} / \mathrm{m}^{3}\right)\end{array}$ & $\begin{array}{c}\text { Water } \\
\left(\mathrm{Kg} / \mathrm{m}^{3}\right)\end{array}$ & $\begin{array}{c}\text { Sand } \\
\left(\mathrm{Kg} / \mathrm{m}^{3}\right)\end{array}$ & $\begin{array}{c}\text { Aggregate } \\
\left(\mathrm{Kg} / \mathrm{m}^{3}\right)\end{array}$ \\
\hline \hline Concrete & 0.45 & 386 & 174 & 629 & 1,122 \\
\hline
\end{tabular}

degreased by acetone just prior to being placed in the mould. The W/C ratio was kept 0.45 with an air content of $3.5 \pm 1 \%$ and $150 \mathrm{~mm}$ slump value. Mix proportions are shown in the following Table 1.

\subsection{Specimen preparation and scheme}

The standard specimen consisted of a prismatic concrete specimen $(100 \times 100 \times 200 \mathrm{~mm})$ with two $13 \mathrm{~mm}$ diameter steel bars (one bar completely embedded and the other coming out from both faces, both having a clear cover of $15 \mathrm{~mm}$ ) cast in steel molds. The reason for using two steel bars is to make it possible to measure corrosion potential and corrosion mass loss using the same specimen which is the originality of this experiment scheme. The clear cover was kept $15 \mathrm{~mm}$ because it was reported that measured half-cell potential values at concrete surface could be considered as actual value at steel surface, if cover depth was within $20 \mathrm{~mm}^{4}$ The test consists of 24 specimens having a total $\mathrm{Cl}^{-}$concentration varying from $0 \sim 10 \%$ in mixing water consisting of three sets for 20,40 and $60^{\circ} \mathrm{C}$ temperature conditions and $60 \%$ relative humidity in environment control chambers. Half-cell potentials were measured for all specimens using a copper-copper sulfate reference electrode (CSE), in accordance with ASTM C876. Finally the specimens were broken and corrosion mass loss was determined by gravimetric method after standard chemical cleaning of the corrosion products.

\section{Modeling of corrosion}

\subsection{Governing laws and tafel diagram technique}

The corrosion model of DuCOM system has been adopted from the previous research. ${ }^{2,3}$ In the model a general scheme of microcell corrosion is introduced based on thermodynamic electrochemistry. Initially, electric potential of corrosion cell is obtained from the ambient temperature, $\mathrm{pH}$ in pore solution and partial pressure of oxide, which are calculated by other subroutines in the system. The half-cell potential can be expressed with the Nernst Equation. Tafel Diagram ${ }^{5}$ is a useful tool for simulating the corrosion phenomenon of metals. Corrosion potential 'Ecorr.' and corrosion current 'Icorr.' can be obtained as the point of intersection of the two lines in the model.

\subsection{Corrosion in concrete and the effect of $\mathrm{Cl}^{-}$}

Although most corrosion takes place in water, corrosion in nonaqueous systems is not unknown. When it comes to the modeling of corrosion in concrete like steel reinforcement embedded in concrete under the effect of severe environment such chloride attack, then need arises to introduce some semi-empirical equations which logically satisfy the existing corrosion science laws, principals and these equations are also verified by experiments. In modeling of large scale real structures, pure theory becomes insufficient and somehow theory and practice has to be combined together in the form of a semi-empirical-theoretical approach.

\subsection{Anodic tafel gradient factor ' $\mathrm{fp}$ '}

The effect of chloride on corrosion being anodic controlled in nature has been incorporated by varying tafel gradient of anodic reaction 'ba' with free chloride concentration $\left(\mathrm{C}_{\mathrm{Cl}}\right)$ given in Eq. (1) and Fig. 2. ' $\mathrm{i}_{\mathrm{a}}$ ' and ' $\mathrm{i}_{\mathrm{c}}$ ' are electric current densities at anode 


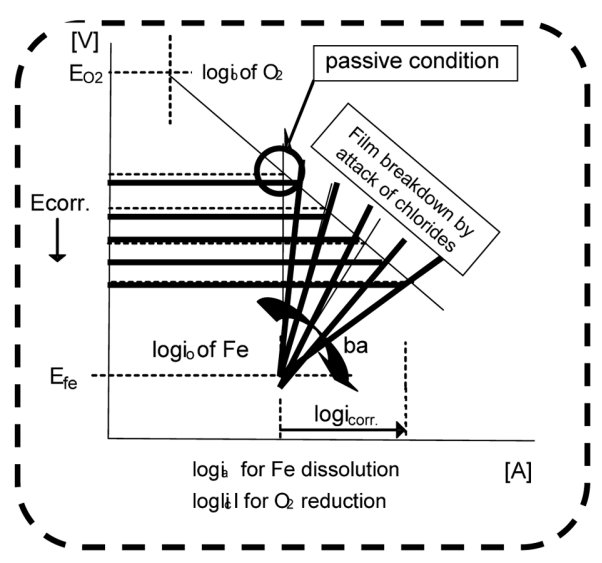

Fig. 2 Potential and current increment by $\mathrm{Cl}^{-}$migration and breakdown of passive layer.

and cathode respectively

$$
\mathrm{ba}=\left(2.303 \mathrm{RT} / 0.5 \mathrm{Z}_{\mathrm{Fe}} \mathrm{F}\right) \mathrm{fp}, \mathrm{fp}=3.17 \times 10^{-2} \mathrm{C}_{\mathrm{Cl}}{ }^{-0.826}
$$

In the model, this semi-empirical-theoretical factor ' $f p$ ' accounts for the change in anodic gradient. When the chloride concentration is zero, the factor ' $f p$ ' becomes infinity and the rebar is considered to be in perfect passive condition represented by a $90^{\circ}$ perpendicular anodic line of the tafel diagram as shown in Fig. 2. As the chloride concentration increases, the passive layer starts breaking simulated by decrease in 'fp' resulting in the fall of anodic gradient moving the point of intersection of anode and cathode lines towards the more negative corrosion potential and increase in corrosion current until the threshold chloride value is reached and the passive layer is completely destroyed. At the threshold chloride value, the passive layer is completely destroyed, thus the factor ' $\mathrm{fp}$ ' becomes 1.0 and the gradient of anodic reaction in the tafel diagram becomes equal to the actual tafel gradient as given by Nernst equation. In the light of past research works the threshold chloride value has been fixed as $0.4 \%$ total chlorides by mass of cement. ${ }^{6-}$

${ }^{11}$ Since the model is based on the amount of free chloride existing in the pore, conversion of free $\mathrm{Cl}^{-}$to bound $\mathrm{Cl}^{-}$and vice versa is done using chloride equilibrium model. ${ }^{12}$

\subsection{Anodic potential factor ' $F_{\mathrm{Cl}}$ '}

It was observed from the experiment results of this research that corrosion rate and potential continuously increases even after the threshold chloride value is reached and the passive layer is completely destroyed. Based on this experimental observation and the theoretical scientific fact that the chloride induced corrosion reaction is anodic controlled in nature, ${ }^{13}$ a semi-empirical factor $\mathrm{F}_{\mathrm{Cl}}$ is introduced in order to initiate anodic potential variation as a function of chloride content as shown in Eq. (2).

$$
\begin{aligned}
& \mathrm{E}_{\mathrm{Fe}}=\mathrm{F}_{\mathrm{Fe}}^{\Theta}+\left(\left(\mathrm{RT} / \mathrm{z}_{\mathrm{Fe}} \mathrm{F}\right) \operatorname{lnh}{ }_{\mathrm{Fe}}^{2+}\right) \mathrm{F}_{\mathrm{C} 1} \\
& \mathrm{~F}_{\mathrm{Cl}}=1+3 \times 10^{-3} \ln \left(10^{4} \mathrm{C}_{\mathrm{Cl}}+1\right)+\left(1.2 \mathrm{C}_{\mathrm{Cl}} /\left(\mathrm{C}_{\mathrm{Cl}}+1\right)\right)
\end{aligned}
$$

This factor ' $\mathrm{F}_{\mathrm{Cl}}$ ' shifts the anodic curve diagonally downwards with the increase in the chloride content, thus moving the point of intersection of cathode and anode polarization curves towards the more negative potential and higher corrosion current direction. In the absence of chloride the factor $\mathrm{F}_{\mathrm{Cl}}$ is equal to one and the anodic potential is equal to the original anodic potential of the tafel diagram given by the Nernst equation as already explained. As the chloride attack becomes active, the factor $\mathrm{F}_{\mathrm{Cl}}$ starts increasing more than 1.0 with the increase in chloride concentration in a non linear path. Refer to Figs. 3 and 4 for further illustration of working of the anodic potential factor ' $\mathrm{F} \mathrm{Cl}$ '.

In this research the model is enhanced from the previous research, ${ }^{14}$ by combining potential and tafel slope models to execute at the same time as both the tafel anodic slope and potential are influenced by chloride migration. Refer to Fig. 5 for physical meaning and illustration of this enhancement. The adjacent figure shows coupled maneuver path of anodic potential and tafel slope as a function of chloride concentration and breaking of passive layer.

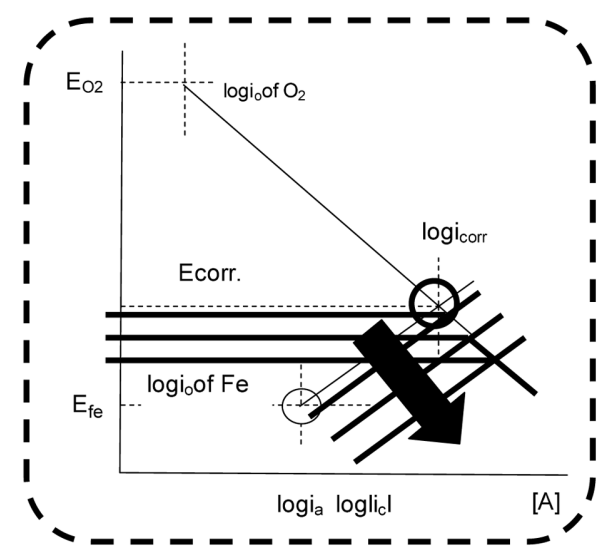

Fig. 3 Illustration of ' $\mathrm{F}_{\mathrm{Cl}}$ '.



Fig. 4 Anodic potential factor ' $F_{\mathrm{Cl}}$ '.

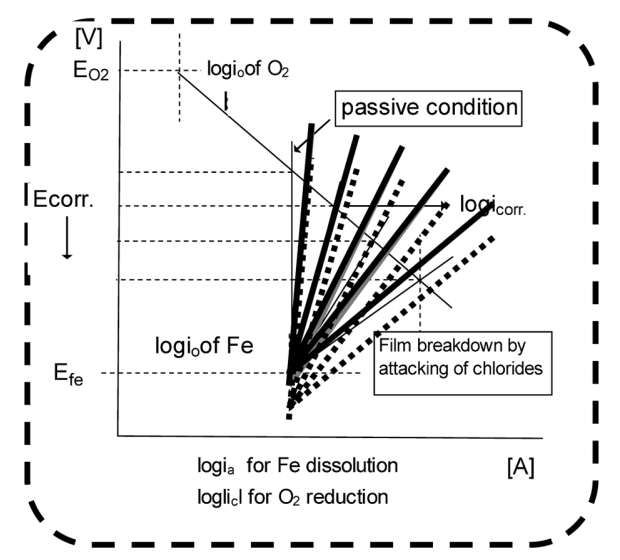

Fig. 5 Coupling of ' $\mathrm{fp}$ ' and ' $\mathrm{F}_{\mathrm{Cl}}$ '. 


\section{Results and discussions}

Results of half-cell potential and corrosion rate measurements for ordinary Portland cement concrete mixed with 0.0, 0.025, 0.25, $0.6,1.0,1.82,3.65,6.0,8.0 \& 10.0$ percent chloride by mass of binder and three temperature conditions of 20,40 and $60^{\circ} \mathrm{C}$ respectively are shown in Figs. 6 and 7. The half-cell potential values for various cases have a tendency to increase in early age and then approach to certain less variable values but not strictly constant. In general the corrosion potential and corrosion rate show a non-linear increase with the increase of chloride content and temperature as shown in Figs. 6 and 7. But, only in the case of the specimens having the high concentration of $\mathrm{Cl}^{-}$and highest tem-

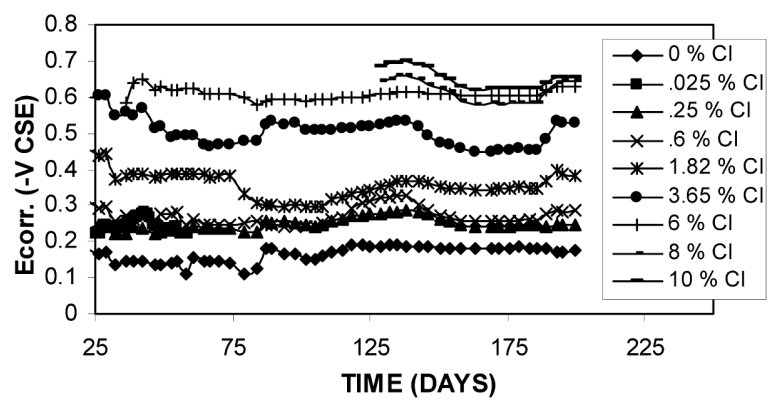

Fig. 6 Variation of half-cell potential with age, $\mathrm{Cl}^{-}$and temperature $(\mathrm{OPC}, \mathrm{W} / \mathrm{C}=0.45)$ (representative results for $20^{\circ} \mathrm{C}$ temperature).

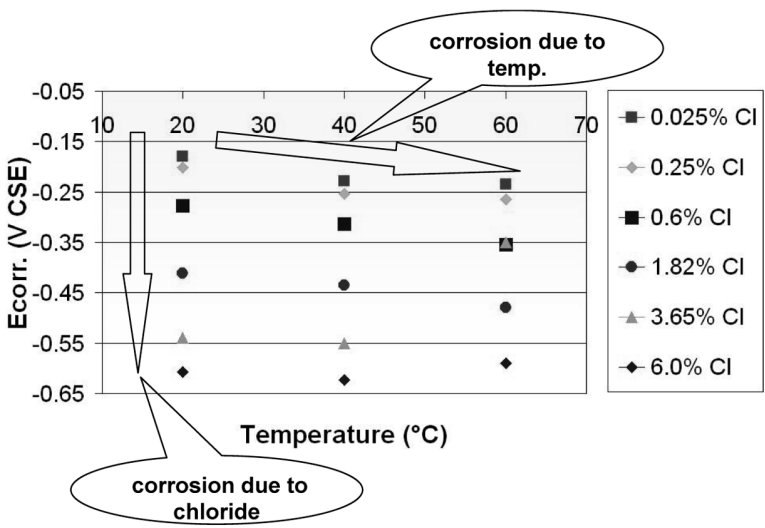

(a) Corrosion potential

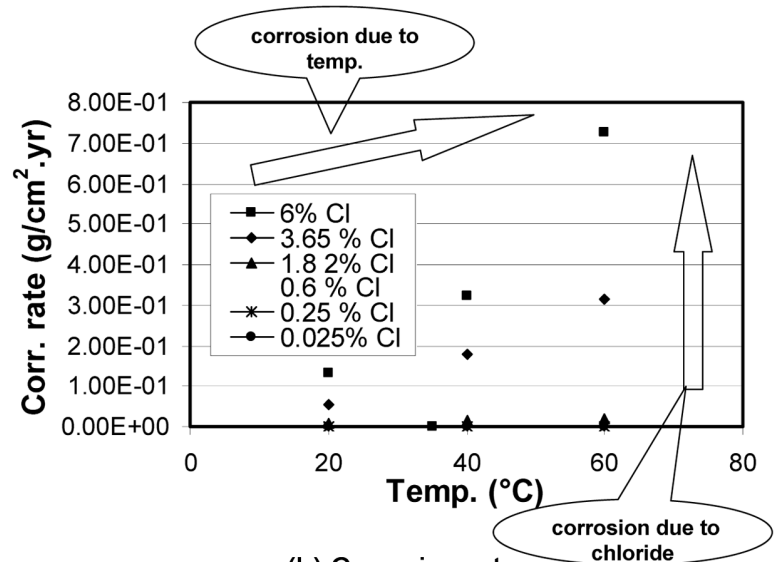

(b) Corrosion rate

Fig. 7 Coupled effect of chloride and temperature. perature show a falling trend and reduction in the corrosion potential values with the increase in temperature. The possible reason could be intensive corrosion cracking occurred in these specimens. Thus causing the loss of moisture needed for corrosion process and discontinuity of the specimen materials between steel and concrete along the crack.

\section{Verification of the model}

DuCOM model for corrosion shows good agreement with the experiment results as shown in Figs. 8 and 9 for the effect of chloride on corrosion of steel reinforcement embedded in concrete for both corrosion potential and corrosion current. Thus, providing evidence for the efficiency and accuracy of the model. The model though is simple but predicts well taking into account influential parameters involved in the process of corrosion in RC structures. Modeling and verification for the effect of temperature is in the pipeline and will be published soon. According to ASTM standard C-876, the reinforcement steel bar in concrete is prone to be under the attack of corrosion if the half-cell potential value is below -0.2 volts. Above that value the steel is in satisfactorily safe condition. The same criterion is also verified by the corrosion model under discussion. In case of chloride induced corrosion, the initiation of corrosion takes place at the threshold value which is mostly considered to be around $0.4 \%$ total chlorides by mass of binder and the model under discussion gives a corrosion potential of -0.21 volts at this value which is just below the value of corrosion potential specified by standards for the detection of initiation of corrosion. Therefore, the corrosion model of DuCOM is also verified by the ASTM Standards in addition to the experimental verification provided in this paper. The corrosion model gives the value of corrosion potential 'Ecorr.' in SHE (Standard Hydrogen Electrode) or NHE (Normal Hydrogen Electrode) units. Therefore, in

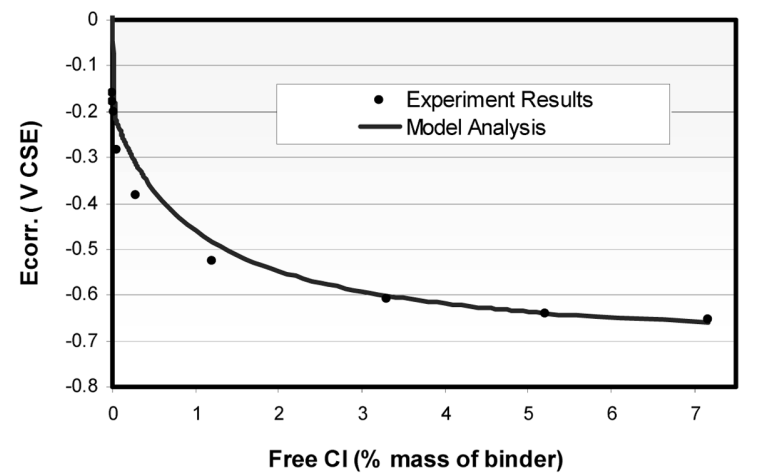

Fig. $8 \mathrm{Cl}^{-}$vs Corrosion potential profile $\left(\mathrm{T}=20^{\circ} \mathrm{C}, \mathrm{W} / \mathrm{C}=0.45\right)$.

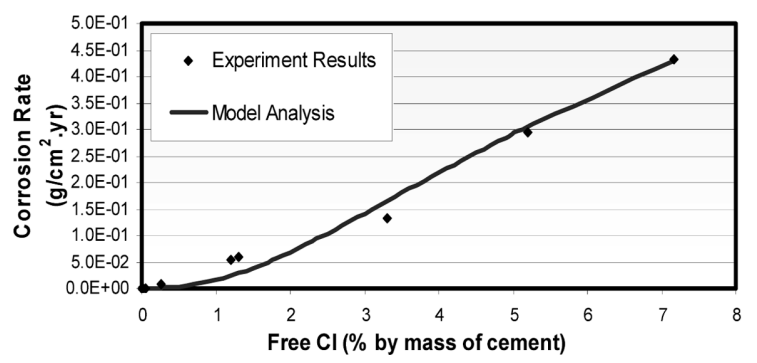

Fig. $9 \mathrm{Cl}^{-}$vs corrosion current profile $\left(\mathrm{T}=20^{\circ} \mathrm{C}, \mathrm{W} / \mathrm{C}=0.45\right)$. 
order to compare it with experiment results which are in CSE (Copper-Copper Sulfate Electrode) units, a standard conversion factor $(\mathrm{CSE}(\mathrm{V})=\mathrm{SHE}(\mathrm{V})+0.316 \mathrm{~V})$ is employed.

\section{Conclusions}

From the experiment results and numerical simulation it can be concluded that corrosion in steel reinforced concrete structures continuously increases in a non-uniform manner even at high chloride concentration in high temperature range. It should not be considered that there is a threshold limit after which the corrosion rate because constant irrespective of the concentration of chloride and the rise in temperature. It is found that the gradient of corrosion profile with temperature becomes significantly steep with the increase in chloride concentration. Influential parameters on prediction of corrosion in RC structures involving the severe environmental loadings of chloride and temperature variation are experimentally determined and numerically discussed through parametric study. Appropriate parameters for material modeling of corrosion on the basis of already developed computational scheme are successfully identified. The model being in close agreement with the experiment results predicts the corrosion rate and potential with good accuracy and precision.

\section{References}

1. Nishida, T., Otsuki, M., Baccay, A., and Hamamoto, J., Temperature Dependency of Corrosion Rate of Steel Bars in Concrete Influenced by Material Segregation, Tokyo Institute of Technology, Toa Corporation, Japan, 2005.

2. Ishida, T., "An Integrated Computational System of Mass/ Energy Generation, Transport and Mechanics of Materials and Structures," Thesis (PhD), University of Tokyo, 1999.

3. Maekawa, K., Ishida, T., and Kishi, T., "Multi-Scale Modeling of Concrete Performance," Journal of Advanced Concrete
Technology, Vol. 1, No. 2, 2003, pp. 91 126.

4. Uomoto, T., Non-Destructive Testing in Civil Engineering, Elsevier, 2000, pp. 671 678.

5. Tafel, J., Zeitschrift Für Eleckrochemie, 1906, pp. 112 122 (In German).

6. Oh, B. H. and Jang, B. S., "Chloride Diffusion and Corrosion Initiation Time of RC Structures," Proceedings of the International Workshop on Durability, Sapporo, Japan, 2004.

7. ASTM C 876-91, Standard Test Method for Half-Cell Potentials of Uncoated Reinforcing Steel in Concrete, ASTM, USA, 1999.

8. ASTM G1-03, Standard Test Practice for Preparing, Cleaning and Evaluating Corrosion Test Specimens, ASTM, USA, 2002.

9. BS 8110, Structural Use of Concrete, Code of Practice for Design and Construction, 1997.

10. ACI 222R-96, Corrosion of Materials in Concrete, 2001.

11. Evertte and Treadaway, "Pore Solution Composition and Chloride Binding of Silica Fume Cement Pastes," Journal of Materials and Structures, Vol. 16, No. 1, 1983, pp. 19 25.

12. Ho Thi Lan Anh, "Modeling of Chloride Transport under Arbitrary Temperature," Master Thesis, University of Tokyo, 2005.

13. Glass, G K., Page, C. L., and Short, N. R., "Factors Affecting the Corrosion Rate of Steel in Carbonated Mortars," Corrosion Science, Vol. 32, No. 12, 1991, pp. 1283 1294.

14. Ishida, T. and Hussain, R. R., "Coupled Effect of Chloride and Temperature on the Corrosion of RC Structures Based on Thermodynamic Approach," The Tenth East Asia-Pacific Conference on Structural Engineering and Construction (EASEC10), Bangkok, Thailand, 2005.

15. Raupach, M., "Investigation of the Influence of Oxygen on Corrosion of Steel in Concrete, Part I and II," Journal of Materials and Structrues, Vol. 29, No. 3, pp. 174 184, and Vol. 29, No. 4, 1996, pp. 226 232. 